\title{
Design and Application of a General-purpose \\ E-learning Platform
}

\author{
Xiaolin Chen \\ (School of Business Administration, Northeastern University \\ Shenyang 110004, China \\ E-mail: xlchen@mail.neu.edu.cn
}

\begin{abstract}
In this paper, a general-purpose framework for e-learning platform is designed based on B/S structure. The development steps are put forward. Moreover, the key technologies of the platform are introduced, and then the applications of the e-learning platform are discussed.
\end{abstract}

Keywords: Network, Teaching platform, E-learning, Application mode

\section{Introduction}

The twenty-first century is an era of information technology. With the development of the multimedia technology and network technology, the multimedia technology and the Internet combined to a greater extent. Their application in teaching has brought about tremendous opportunities and challenges to the traditional education. Not only did it expand the teaching content, but also gradually change people's education concept; Further more, it also require new teaching and learning environment. Therefore, how to construct the current network conditions for multi-media teaching and learning environment, make full use of the multi-media teaching network, and improve teaching effectiveness, is becoming an important task for all educators and teachers.

\section{Content, characteristics and situation of e-learning platform}

\subsection{Content of e-learning platform}

The content of e-learning platform is the learning environment achieved through the use of computer programming, which is built on the network infrastructure. Its background is the teaching information storage database and database management system (DBMS). The future system is the web interface running in a browser.

\subsection{Characteristics of e-learning platform}

The planning and design of e-learning platform must serve the practical education and management, and meet the needs of daily work of teaching and management.

\section{(1) Collaborative interaction}

E-learning platform must support the interaction and collaboration among the objects, including the two-way transfer of information and interaction between two groups of students and between teachers and students.

(2) Openness

E-learning platform should have openness, mainly in terms of time, space and the object. That is, the objects can get access to the information through the system at any time and in any place. Or they can have real-time or non-real-time exchange of information with other objects who have different social background.

\subsection{Situation of e-learning platform}

According to statistics, in the United States, the number of people learning through the e-learning platform is growing at the rate of more than 300 percent every year. Till 1999, there were more than 70 million Americans who had acquired knowledge and skills through online education. More than $60 \%$ of the companies finished their staff training and continuing education through online education. In the UK, the government's investment in online education is also very large. Almost all the schools have set up their own online schools. China's Ministry of Education has put forward the concept that "education must be promoted through the modern information technology in education." In recent years, 
with the development of "Connecting Schools Project" and "Western University Campus Network Project", many schools have set up their own online learning platform on the base of campus network., and have launch teaching activities on the base of online teaching platform.

At present, there are a number of easy-to-use and efficient online learning platforms overseas, such as Learning Space of Lotus, WebCT (Web Course Tools) of Columbia University, Top Class of WBT System and Virtual-U of Simon Fraser University, Canada. There are also many domestic companies and schools who have developed or are going to develop similar E-learning platforms. Major universities have developed teaching supporting system in preparation for the development of modern distance learning and teaching system. Tsinghua University Network, which is the supporting platform of Tsinghua online teaching system, has been put into operation.

\section{Analysis of E-learning platform requirement}

E-learning platform carries out for the use of the online exchanges between teachers and students. Its main function is to provide interactive environment for teachers and students. The analysis of specific functional are as follows:

(1) Information bulletin. Teachers publish the teaching-related information and the students check the information timely.

(2) Introduction of teachers and courses. Introduction of teacher and school courses, credits and other related information.

(3) Watch courseware. By real-time playback and synchronization of the writing content on the blackboard (mostly PowerPoint or HTML-based script), students can learn course by themselves.

(4) Download courseware. Students can download the courseware, and teachers upload to support the self-study after school hours.

(5) Operations management. Students download the homework, complete operations and submit to the teachers, and check their grades in time.

(6) Teacher-student interaction. Teachers and students exchange questions and answers online in real-time. Students and teachers can also communicate non-real-time interaction by way of sending instation message or E-mail.

(7) Management module. This area is divided into teacher section and administrator section. Teachers published information on the dynamic course, upload courseware and homework, manage user rights of the students. Administrator work for day-to-day maintenance of the e-learning platform.

(8) Online test. Students can select in the examination questions for online test and check test results.

E-learning platform breaks the constraints of time and space in traditional education. It is an extension of the classroom teaching, and thus is better adapted to modern society's "life-long learning" atmosphere.

\section{Construction of e-learning platform framework}

\subsection{The overall framework}

The overall framework of the application objects are classified into three sub-platform systems according to students, teachers, the management. The three sub-platform systems will split various functional system and then combine again, to form the framework combined with vertical function system and nichorizontal application object, to complete the function of all systems through the integration of the three sub-platform, as is shown in Figure 1.

Insert Figure 1 here

\subsection{Application Mode}

The online learning system is designed using the three-layer B/ structure, as is shown in Figure 2. End users requests to the server from the browser, using ASP technology to acquire user request information. When the request information is integrated with the background databases, the information is handled by means of connecting the databases through ODBC, and the handled information will be sent back to the users through ASP.

The greatest advantage of the use of $\mathrm{B} / \mathrm{S}$ structure is that users can log in online learning platform through the browser, with no need to install any client software, and it has no regional limitation.

Insert Figure 2 here

\subsection{Functional Design}

According to the overall block diagram of e-learning platform shown in Figure 4.1, the specific design features of e-learning platform are as follows:

(1) Teachers Corner. To support the teaching activities on the net. Teachers can publish courseware and teaching information in the "Release Management" sub-module; upload homework and correct on line in the "Job Management" sub-module; add, delete or modify in the course information in the "Course Management" sub-module, in order to make 
students more aware of the selected course information; maintain the information of students, which can be used as the basis of dynamic allocation of the administrator.

(2) Site management. To initialize the site information and daily maintenance. Administrator can do the maintenance of online information, forums, update the user information and operate the dynamic allocation of authority.

(3) Login. To validate visitors authority to the use of e-learning platform.

(4) Course description. To introduct information on the courses.

(5) About teachers. To introduct information for teachers.

(6) Courseware download. To download coursewares used by students.

(7) Homework Management. To download the homework, upload finished homework, and check grades.

(8) Online learning. To learning the courseware on the e-learning platform

(9) Online test. To test students and issue results.

(10) Teacher-student interaction. To provide the interactive channel between teachers and students. Teachers and students can interact by means of sending E-mails and instation message. They can also exchange ideas through the online Q\&A forum.

\subsection{Key technologies and tools of e-learning platform}

The main technology and tools of e-learning platform includes:

(1) ASP language. ASP (Active Server Pages) is one of popular web application program development languages. ASP is produced and executed on the website server with high interaction and high efficiency.

(2) Dreamweaver MX. This is one of the most popular web site authoring tools. It is equipped with a full suite of page design tools and web site management tools. It can set up, manage and modify websites rapidly, providing HTML/DHTML, Java Applet, ASP 2.0, JSP 1.0 as well as development tool module such as CSS style to achieve "WYSIWYG" effect.

(3) Microsoft SQL Server. It is a Microsoft database product introduced for the large network environment. Taking into account the actual situation of teaching and the using easiness and stability of Microsoft SQL Server database, it uses Microsoft SQL Server 2000 database.

\section{Application of e-learning platform}

Upon completion, the e-learning platform has been applied in some courses. It greatly improved the quality of teaching. The advantages are as follows:

(1) Traditional paper-based homework and reports are upgraded to electronic documents. It is a reform for a variety of homework and media for report.

(2) The traditional scoring means is replaced by the time-saving and effort-saving web form score means, with no time and space constraints. Teachers are saved from chore of repeated finding, checking, cumulating scores and so on.

(3) Online Q\&A has improved the efficiency of the teacher-student interaction. The traditional one-on-one teaching is changed into one-to-many teaching in time and space. Students can see how teacher answer the issues raised by themselves and others, thus enhancing the efficiency of the exchange.

\section{References}

Biao H. (2004). Techniques and examples of ASP network programming. Beijing: Posts \& Telecom Press, 355-360.

Jones G.. (1995). Categorizing distance learning systems discovering successful ingredients. Proceedings of the sixth IFIP World Conference on Computers in Education, 243-249.

Li, X. (2004). Dreamweaver MX in Chinese 2004 Platinum Teaching, Beijing: Ordnance Industry Press, Beijing Kehai Electronic Publishing, 192-202.

Studio L. (2005). Dreamweaver MX 2004 \& ASP Dynamic Web Page Programming Self-manual, Beijing: Posts \& Telecom Press, 105-110.

Weiyuan Z. (2005). The analysis of e-learning platforms and web site building in colleges and universities. Practice and Exploration.

Yin M. (1999). Development and Application of A Web-Based Supervised Integrated Distance Teaching \& Learning Environment. ICDEDL International Conference (Beijing).

Zhixing L, Qingsheng Z, \& Yi Z. (2008). The Development and Construction of Java EE Technology-based Experiment Teaching Platform, Technology Applications. 


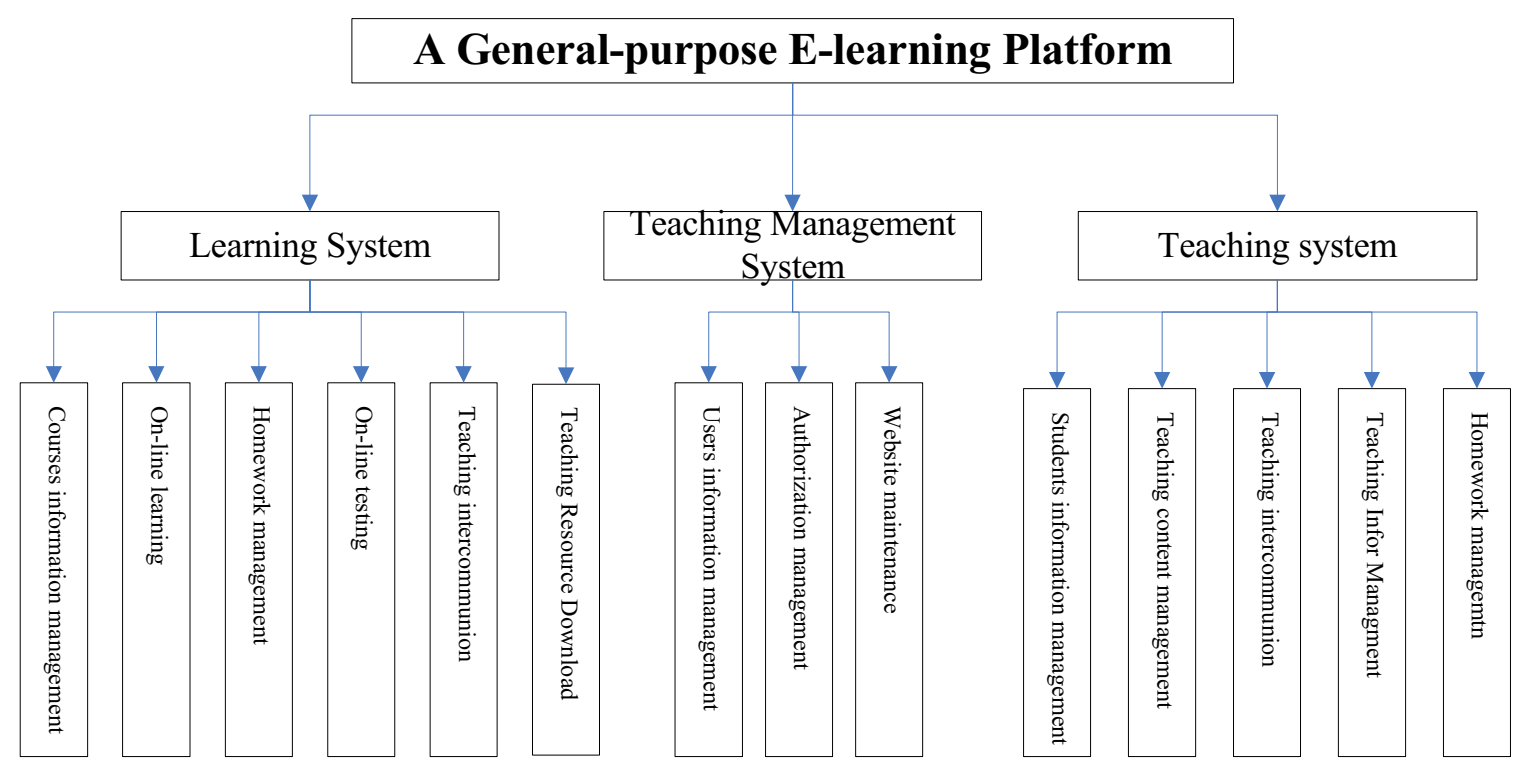

Figure 1. E-learning platform for the overall model framework

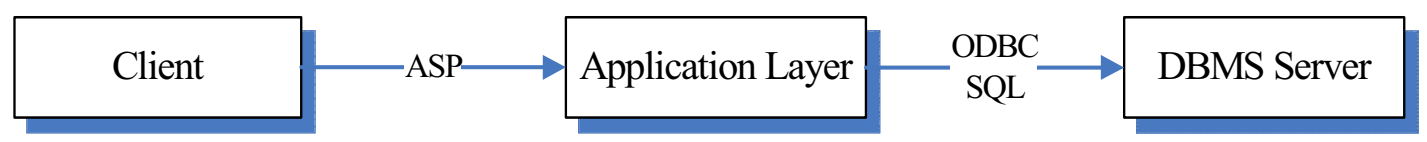

Figure 2. B/S structure of E-learning platform mode 